\title{
Resolving the trade-off between production and biodiversity conservation in integrated forest management: comparing tree selection practices of foresters and conservationists
}

\author{
Hannes Cosyns ${ }^{1}$ (D) - Bettina Joa $^{2} \cdot$ Ronja Mikoleit ${ }^{3} \cdot$ Frank Krumm $^{1}$ • \\ Andreas Schuck ${ }^{2} \cdot$ Georg Winkel ${ }^{2} \cdot$ Tobias Schulz $^{1}$
}

Received: 23 July 2019/Revised: 2 September 2020 / Accepted: 3 September 2020 /

Published online: 12 September 2020

(C) The Author(s) 2020

\begin{abstract}
Integrating nature conservation effectively in forests managed for timber production implies reconciling a trade-off between ecological and economic objectives. In continuous cover forest management, this culminates in decisions about tree harvesting (or retention) determining both the prevalence of tree-related microhabitats in the forest and the economic viability of timber management. Applying an innovative mixed methods approach, we compare conservationists and foresters performing a tree selection exercise. We assess the outcomes of their forest management decisions quantitatively and explore their strategies and the underlying reasoning based on qualitative data. Our findings show that particularly the habitat trees differ greatly between the two groups: while conservationists retained almost exclusively large oaks at often high opportunity costs, foresters retained a notable number of smaller-diameter hornbeams. These differences are related to a different perception of opportunity costs of retention by both groups, as well as because they do not agree about how to value current tree-related microhabitats and their projection into the future. Such diverging patterns of reasoning imply incompatible interpretations of what constitutes a habitat tree. Our results indicate that it is important to apply benchmarks for evaluating ecological goals as well as to increase foresters' and conservationists' understanding about the motivations and restrictions of the respective counterpart. Our study points out a significant potential for (mutual) learning, and illustrates the complementarity of quantitative and qualitative research methods to examine tree selection behaviour.
\end{abstract}

Keywords Habitat trees - Marteloscope - Tree-related microhabitats - Mixed methods · Economy-ecology trade-off · Integrated nature conservation · Opportunity costs

Communicated by Daniel Sanchez Mata.

This article belongs to the Topical Collection: Forest and plantation biodiversity.

Electronic supplementary material The online version of this article (https://doi.org/10.1007/s10531-02002046-x) contains supplementary material, which is available to authorized users.

Extended author information available on the last page of the article 


\section{Introduction}

Integrating biodiversity conservation measures in forests managed for commodity production is crucial to reach biodiversity conservation goals (Gustafsson et al. 2012). In forests managed for timber production, which typically lack structural elements relating to old-growth phases and considerable amounts of deadwood, this requires a significant and well distributed presence of so-called old growth characteristic (Bauhus et al. 2009), including tree-related microhabitats (TreMs; i.e. tree cavities, bark pockets, dead branches or trunk rot; see Larrieu et al. 2018). In continuous cover forestry - the predominant forest management paradigm in Central Europe being characterized by the absence of clearcutting, and labelled as a global trend in forest management (Gustafsson et al. 2020; Puettmann et al. 2015) - a key measure is to select and retain individual trees which bear these TreMs, further called habitat trees (Bütler et al. 2013).

Habitat trees can exhibit many structures that negatively affect their commercial value, e.g. tree cavities, stem breakages or debarked stems. The timber value of such trees (e.g. oak trees) can still be considerable, though, and excluding them from the economic value chain through retention can imply a noticeable economic loss (Niedermann-Meier et al. 2010; Santopuoli et al. 2019). Furthermore, they might occupy growing space over several rotations ages, with increasing safety risks and thus cost implications also for nearby forestry operations. Thus, selecting and retaining potential habitat trees in forest management in the context of continuous cover forestry impacts both economic viability of wood production and the conservation value of the remaining forest stand (Santopuoli et al. 2019).

Understanding tree selection has long been neglected in research. Only recently studies emerged, indicating i.a. that several factors related to individual's expertise can be important for tree selection (Cosyns et al. 2018; Pommerening et al. 2018; Spinelli et al. 2016; Vitkova et al. 2016). Correspondingly, empirical implementation research points to the crucial role of forest managers for the success of integrated nature conservation policies. Forest managers face the need to resolve the trade-off between wood production and biodiversity conservation. Forest management plans usually identify trade-offs but they give only vague indications about how to solve them (Winter et al. 2014). For habitat tree selection, the local forest manager (or other person selecting the trees) is often left with little guidance, especially also relating to trade-offs between conservation and economic goals, and how to cope with them (Maier and Winkel 2017).

While tree selection in continuous cover forestry is certainly dependent on individual experience and expertise, also professional education, socialization and habitual professional knowledge influence the decision-making processes (Maier and Winkel 2017; Spinelli et al. 2016). So far, studies of tree-marking have compared subjects with rather similar professional background (foresters, forestry trainers, loggers, agronomists) (Pommerening et al. 2018; Spinelli et al. 2016; Vitkova et al. 2016). Also, they only consider outcomes related to wood production and are based on a purely quantitative research design by looking at the outcomes of the decisions exclusively, without considering individuals' justifications more in detail. This paper addresses this gap by examining the tree selection behaviour of two groups with very different professional backgrounds that are critical for the success of an integration of biodiversity conservation in productive forest management, i.e. conservationists and forest managers. The objective of the paper is to explore in what way distinct professional backgrounds determine how sustainable wood production and biodiversity conservation are being integrated through tree selection 
practices. We apply a mixed methods approach (Creswell and Clark 2017), and thus derive insights from the analysis of both quantitative and qualitative data. Specifically, in addition to quantifying the selected trees for their conservation and economic values, we use qualitative data to explore the strategies applied and the respective reasoning of the participants when selecting them. Analysing both quantitative data on tree characteristics and qualitative justifications of tree selection decisions together provides novel insights into how which trees are selected by different relevant professional groups. By doing so, this article goes beyond existing studies on tree selection which solely rely on quantitative data (Cosyns et al. 2018; Pommerening et al. 2018; Spinelli et al. 2016; Vitkova et al. 2016), and aims to also provide insights into the motivations for tree selection. The latter is specifically relevant for conservation policy to guide practical implementation of integrated forest management strategies.

\section{Methods}

\section{Site location and properties}

The tree selection exercises analysed in this paper took place in the marteloscope Jägerhäuschen which is part of a European network of marteloscopes (InForMAr 2018) facilitated by the European Forest Institute, focussing on the integration of biodiversity conservation into forest management. Marteloscopes are delineated plots in forests where all trees are numbered and mapped. Their main purpose is to allow the simulation of tree selection, particularly in the context of continuous cover forestry (Kraus et al. 2018).

In the marteloscope Jägerhäuschen, all trees larger than $7.5 \mathrm{~cm}$ in diameter at breast height $(\mathrm{DBH})$ are inventoried and determined (species, DBH, volume). The timber quality of each tree is estimated by the local forester and then its economic value (measured in Euros) is calculated based on the available volumes of timber of different quality classes multiplied by local wood prices. TreMs are assessed according to their type, size and developmental stage based on the catalogue of tree microhabitats of Kraus et al. (2016a). A tree's habitat value (measured in habitat points) is calculated as a composite index based on (a) the type and number of TreMs on a given tree, (b) their rarity and (c) the time a specific TreM needs to develop. More information on the assessment of the economic and habitat value of the trees can be found in Kraus et al. (2018).

Jägerhäuschen was established in 2017 in the Kottenforst (North Rhein-Westphalia, Germany, near Bonn) according to the methodology defined in Schuck et al. (2015). The stand is rectangular, 1 ha in size and consists of 217 stems $>7.5 \mathrm{~cm}$, a basal area of $30.7 \mathrm{~m}^{2} /$ ha and a total standing wood volume of $416 \mathrm{~m}^{3}$. It is a two-layered stand (Fig. 1) with large pedunculate oak (Quercus robur) in the upper layer and smaller hornbeam (Carpinus betulus) in the lower layer as well as a minor presence of beech (Fagus sylvatica).

\section{Complementary mixed methods}

We employ a causal-comparative design in this paper (Brewer and Kuhn 2010), similar as other scholars who have been investigating tree selection behaviour (Spinelli et al. 2016; Vitkova et al. 2016; Cosyns et al. 2018). In our study, we compare a rather homogenous group of foresters with a rather homogenous group of conservationists deciding about habitat tree retention and removal of trees on the same marteloscope on two consecutive 


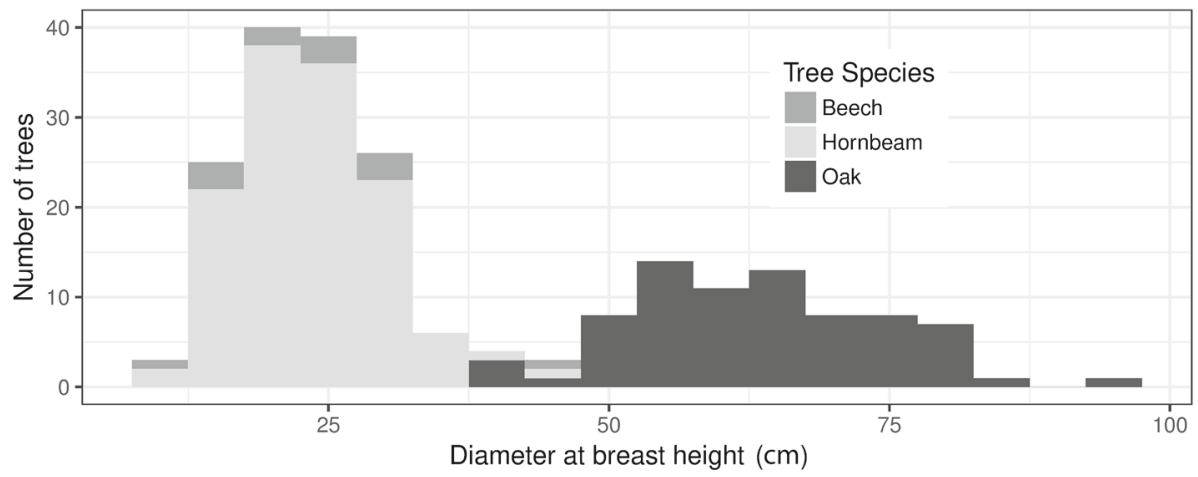

Fig. 1 Diameter frequency distribution of the marteloscope Jägerhäuschen

days. In examining the two groups, we followed a mixed methods approach, combining quantitative and qualitative empirical social research (Tashakkori and Teddlie 2010). We examine the (quantitative) characteristics of the trees marked for removal and retention and collect additional data with a small questionnaire during the exercises. Our sample is small, covering one case only, and the quantitative data alone does not provide sufficient grounds for firm causal inference. Yet, we include qualitative social empirical data from observations and group discussions following the exercises to substantiate the analysis. This enables us to reconstruct patterns of action, shared opinions, and reasoning as well as implicit knowledge and routinized practices applied in tree selection. Understanding this process of decision making in depth allows, in turn, for some generalization beyond the single case examined. With that, the paper follows the suggestion of several scholars to employ qualitative social science approaches when aiming to better understand human decisions-such as tree selection-in forestry (Bennett et al. 2017; Charnley et al. 2017; Mascia et al. 2003).

\section{The marteloscope exercises, sampling and data collection}

On November 13th and 14th, 2017, two marteloscope exercises took place in Jägerhäuschen under similar weather conditions. The exercise on the first day was attended by twelve persons: one forestry student and nine nature conservation professionals (in the following labelled conservationists) and two foresters. While the forestry student was participating as a delegate of the regional nature conservation organization, the results of the two foresters participating on day one were not used in the quantitative analysis below because they were accompanying as responsible persons of the local forest enterprise and not invited as conservationists. The exercise on the second day was attended by twelve persons, which were all active in forest management (thus labelled foresters hereafter) as members of the state forest enterprise. On both days six additional persons were present without participating in the exercise: two marteloscope experts organizing and guiding the marteloscope exercises (called trainers hereafter), the local forest enterprise head, and three researchers.

The exercise proceedings were the same on both days (Fig. 2). First, participants were given a general introduction to the marteloscope by the trainers. Afterwards, the local forest enterprise head provided instructions for tree selection that were formulated in accordance to local forest management practice: 


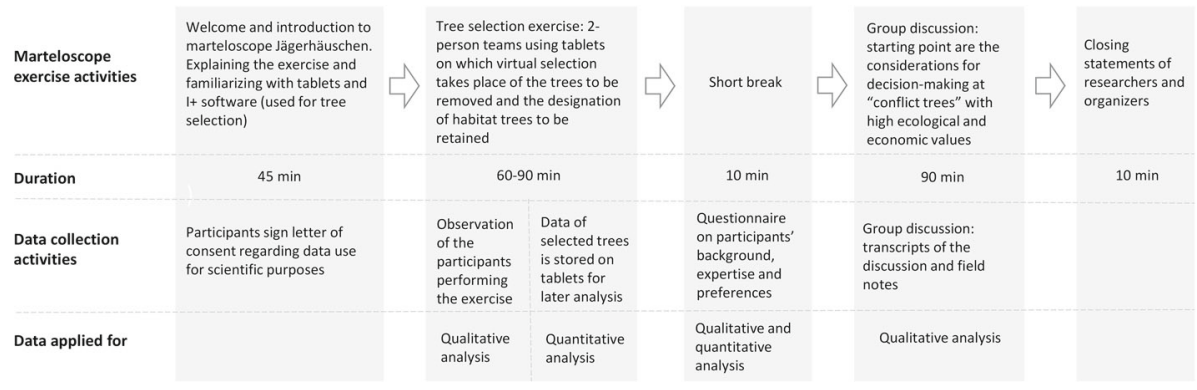

Fig. 2 Chronological overview of the marteloscope exercise and corresponding data collection activities

"Removal of $50 \mathrm{~m}^{3}$ wood (low removal rate, harvest should include $10 \%$ high-quality timber) and designation of 10 habitat trees".

Next, tablets equipped with the "I + " software (Kraus et al. 2016b) were handed out. The "I + " software displays an interactive map of the forest stand, allowing participants to select or deselect individual trees for removal or retention. Hence, the tablet mainly served as a selection device, replacing pen and paper. The tablet provides information on each tree's species, its spatial location (map), DBH and the sum of DBH for all selected trees. It did not provide any information on the economic or conservation value of the trees. Subsequently, the tree selection exercise took place in two-person teams, with one tablet per team. In the remainder of this text and in the following tables and figures, we identify the five teams of conservationists as $\mathrm{C} 1$ to $\mathrm{C} 5$ and the six teams of foresters as F1 to F6. The teams walked freely for one and a half hour through the marteloscope site and virtually selected trees with the software.

The combination of empirical methods applied to analyse the exercise is displayed in Fig. 2. It encompassed the following steps:

Observation of the participants during tree selection exercise The three researchers accompanied some teams during the actual marteloscope exercise, listening and taking notes of their discussions and interactions during the tree selection process.

Virtual forest management interventions practiced on tablets The "I+" software on the tablets recorded the tree selection outcomes of the groups and thus a broad set of variables is available: species, DBH, overall volume and economic value, as well as volume and value of wood assortments of different quality, the number and type of TreMs and their corresponding habitat values.

Questionnaire After the tree selection exercise, all teams filled in a questionnaire, containing questions for the individual participants as well as questions to be responded at the team level (see online supplementary material). The questionnaire inquired about profession and education with respect to forestry and ecology (questions 2-9), the teams' preferences concerning the trade-off between ecological and economic objectives (question 10) as well as some questions about the weight given during the tree-selection exercise to various objectives that might be important for habitat tree and thinning or crop tree selection.

Group discussions Both exercises ended with a group discussion, each about $90 \mathrm{~min}$, during which two or three so-called "conflict trees" of both high ecological and economic value were revisited. The two marteloscope trainers asked the teams about their general approach in tree selection and the more specific considerations when deciding about 
particular trees. This was supplemented by selected questions from the researchers. This setting allowed the participants and trainers to moderate the group discussion, and point to important observations and insights from the exercise (Nyumba et al. 2018). Observing and analysing this process of communication and interaction allows to obtain insights into common patterns of understanding and meaning that structure opinions and attitudes (Bohnsack et al. 2010; Lamnek 2005).

\section{Data analysis}

\section{Assessing the quantitative results of the virtual intervention}

First, we compared the outcomes of the virtual tree selections between foresters and conservationists regarding both, the removal of trees and the designation of habitat trees, looking at the number, species, size and economic values of the trees as well as the TreMs. We generated simple contingency tables (Chi-squared test), and compared means based on t-tests, taking into account that the chosen trees are clustered according to teams. We did not apply statistical tests on the aggregated level (i.e. comparing team results) due to the small sample size. Instead, the analysis was based on a qualitative (visual) assessment of frequencies and plots.

Next, to examine the trade-off between ecological and economic objectives participants had to cope with, we looked at the ratio between a tree's economic value and its habitat points. For tree removal, we call this economic revenue per habitat point, as it indicates how much money was obtained for waiving a certain amount of habitat points. For habitat tree retention, though, we will call this ratio the opportunity cost of tree retention, as it indicates how much economic value had been given up per habitat point retained. Regarding habitat tree retention, we have plotted the aggregated habitat and economic value of the habitat trees retained per team (compare Fig. 5 below), in order to visually compare the teams' results.

\section{Assessing perspectives and strategies in tree selection from qualitative data}

Both group discussions mentioned above were recorded and transcribed verbatim. For the analysis of the transcripts, we used a composite strategy, combining elements from classic qualitative content analysis (Mayring 2014) complemented by a reconstructive interpretation of key passages with selected interpretative foci suggested by Kruse (2015). Focusing on participants' arguments, we analysed the data in two phases: Firstly, we assigned codes to text passages and developed a broad categorization of arguments. This categorization reveals different decision-making practices when facing trade-offs in integrated forest management. Secondly, we applied an interpretive lens: We analysed specific arguments, wording, narrative figures, metaphors etc. in key passages about 'conflict trees' and opposing tree selection strategies with the goal of reconstructing subjective sensemaking processes in relation to tree selection (Ivanoff and Hultberg 2006; Kruse 2015).

This analysis was done by two researchers independently from each other, facilitated by exchange and interpretation meetings at regular intervals. Additionally, key passages were assessed in an interpretation group with other researchers in order to broaden the scope of viewpoints and validate existing interpretations. Since both group discussions were held in German, statements cited in this paper are translations conducted by the authors. The three observation protocols resulting from the observatory participation of different research 
teams during the exercises served as complementary data to assess implicit and not verbalized aspects influencing decision-making in tree selection (Merriam 2009). This includes, for example, how participants move through the stand and how they perform an intensive visual inspection of specific trees and tree structures, with some of them using binoculars and some of them not. The intersubjective analysis of these different kinds of qualitative data yields a holistic perspective, allowing us to illuminate the decisive role of routines, individual views and professional contexts for tree-selection practices.

\section{Results}

\section{Removal of trees}

Recalling the silvicultural instruction given to the participants, the presentation of results first displays the volume to be removed (target: $50 \mathrm{~m}^{3}$ ), the inclusion of high quality timber (target: 10\%), and the number of trees removed (target: low removal rate). In addition, we analysed the habitat value of the removed trees. Whereas conservationist teams (virtually) removed a volume of $60 \mathrm{~m}^{3}$ on average, forester teams only selected a slightly higher average volume of $63 \mathrm{~m}^{3}$. The strongest difference between the two groups was however that the foresters removed less trees (13 on average) than conservationist (19 on average). Related to that, the trees removed by foresters had a significantly larger average diameter and volume (Table 1). Furthermore, trees selected by foresters for removal had an average economic value almost twice as high as the conservationist's choices. More importantly, though, the mean proportion of high quality timber extracted by the foresters was $11.8 \%$ and was thus very close to the set $10 \%$-target. The conservationists extracted only $5.8 \%$. It thus appears that foresters complied better with the given economic targets by focussing on the removal of few high-value trees, while conservationists removed more and smaller trees with a lower economic value.

Regarding the habitat value of the removed trees, we did not find any significant difference regarding species composition, (chi-squared-test, $\mathrm{df}=2, \mathrm{p}=0.60$; Table 5 in Appendix), the total number of TreMs per tree or the removed trees' mean habitat value (Table 1) between conservations and foresters. Overall, conservationists removed, on average, trees with a slightly lower habitat value than foresters, but as conservationists selected more trees to be harvested, the average aggregated habitat value removed per team was similar.

Table 1 Characteristics of trees selected for removal by conservationists $(n=95)$ and foresters $(n=80)$

\begin{tabular}{lclllll}
\hline & $\begin{array}{l}\text { Mean } \\
\text { DBH } \\
(\mathrm{cm})\end{array}$ & $\begin{array}{l}\text { Mean } \\
\text { volume } \\
(\mathrm{m} 3)\end{array}$ & $\begin{array}{l}\text { Mean } \\
\text { number of } \\
\text { TreMs }\end{array}$ & $\begin{array}{l}\text { Mean habitat } \\
\text { value (habitat } \\
\text { points })\end{array}$ & $\begin{array}{l}\text { Mean } \\
\text { economic } \\
\text { value (Euro) }\end{array}$ & $\begin{array}{l}\text { High-value } \\
\text { wood (m3) }\end{array}$ \\
\hline Conservationists & 51.1 & 3.17 & 1 & 8.3 & 582 & 0.13 \\
Foresters & 63.1 & 4.78 & 1 & 12.4 & 925 & 0.44 \\
Clustered t-test & $p=0.011$ & $p=0.017$ & $p=0.119$ & $p=0.086$ & $p=0.080$ & $p=0.03$ \\
\hline
\end{tabular}


Table 2 Characteristics of habitat trees selected for retention by conservationists $(\mathrm{n}=50)$ and foresters $(n=60)$

\begin{tabular}{lccccc}
\hline & $\begin{array}{l}\text { Mean } \\
\text { DBH }(\mathrm{cm})\end{array}$ & $\begin{array}{l}\text { Mean } \\
\text { volume } \\
(\mathrm{m} 3)\end{array}$ & $\begin{array}{l}\text { Mean number } \\
\text { of TreMs }\end{array}$ & $\begin{array}{l}\text { Mean habitat value } \\
\text { (habitat points) }\end{array}$ & $\begin{array}{l}\text { Mean economic } \\
\text { value (Euro) }\end{array}$ \\
\hline Conservationists & 67.9 & 5.6 & 2.58 & 35.1 & 697 \\
Foresters & 50.5 & 3.2 & 2.05 & 26.0 & 272 \\
Clustered t-test & $p<0.001$ & $p<0.001$ & $p=0.071$ & $p=0.98$ & $p=0.0023$ \\
\hline
\end{tabular}

\section{Designation of habitat trees}

All but one of the habitat trees retained by the conservationists are oaks, whereas foresters included significantly more hornbeam in their habitat tree selection (chi-squared-test, df $=2, \mathrm{p}<0.001$; Table 6n Appendix). On average, foresters selected habitat trees with a smaller DBH and volume (Table 2). This difference in DBH is due to foresters selecting hornbeam as habitat trees (smaller diameter trees, see Fig. 3) as well as oak of smaller dimension (t-test: $\mathrm{p}=0.009$; Table 3). Habitat values of the retained trees do, however, not yield clearly significant differences between foresters and conservationists (Table 2) and the same holds for the number of TreMs per habitat tree (Table 2).

Habitat trees of foresters have a lower economic value as compared to those of conservationists (Table 2). This because, one the one hand, conservationist retained oaks with almost double the economic value of the oaks that were selected by foresters (t-test: $\mathrm{p}=0.020$; Table 3). On the other hand, forester included hornbeams as habitat trees, which have a much lower economic value than retained oaks (t-test: $p<0.001$; Table 3 ). Also the habitat values of the retained hornbeams (as compared to retained oaks) are significantly lower (t-test: $\mathrm{p}=0.002$; Table 3), as is the number of TreMs (t-test: $\mathrm{p}<0.001$; Table 3). In summary, conservationist and foresters selected habitat trees with similar habitat values,
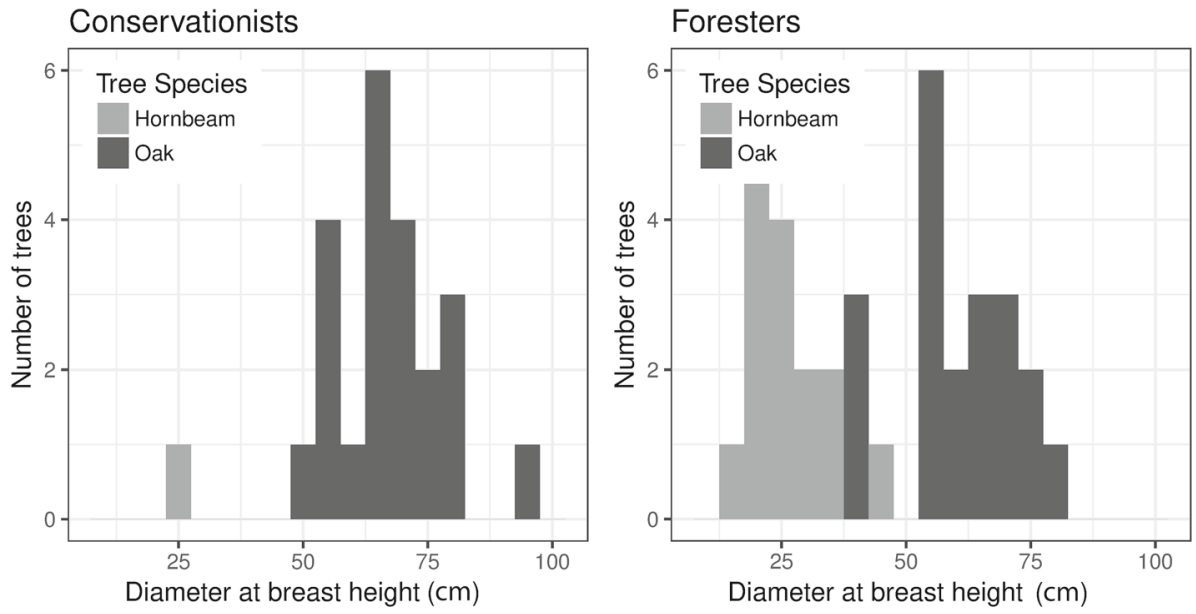

Fig. 3 Frequency distribution of the selected habitat trees according to their DBH and per species, for conservationists and foresters 
Table 3 Attribute values of the selected trees according to their species for conservationists and foresters

\begin{tabular}{|c|c|c|c|c|c|c|c|}
\hline & & $\begin{array}{l}\text { Number } \\
\text { of trees } \\
\text { selected }\end{array}$ & $\begin{array}{l}\text { Mean } \\
\text { DBH } \\
(\mathrm{cm})\end{array}$ & $\begin{array}{l}\text { Mean } \\
\text { volume } \\
\left(\mathrm{m}^{3}\right)\end{array}$ & $\begin{array}{l}\text { Mean } \\
\text { number } \\
\text { of TreMs }\end{array}$ & $\begin{array}{l}\text { Mean habitat } \\
\text { value (habitat } \\
\text { points) }\end{array}$ & $\begin{array}{l}\text { Mean } \\
\text { economic } \\
\text { value } \\
\text { (Euro) }\end{array}$ \\
\hline \multicolumn{8}{|l|}{ Removed trees } \\
\hline \multirow[t]{3}{*}{ Conservationists } & Oak & 58 & 63.1 & 4.78 & 1.0 & 11 & 928 \\
\hline & Hornbeam & 30 & 27.4 & 0.59 & 0.8 & 5 & 35 \\
\hline & Beech & 7 & 31.0 & 1.01 & 0 & 0 & 66 \\
\hline \multirow[t]{3}{*}{ Foresters } & Oak & 61 & 69.2 & 5.87 & 1.3 & 15 & 1187 \\
\hline & Hornbeam & 13 & 32.2 & 0.85 & 1.0 & 7 & 51 \\
\hline & Beech & 6 & 46.0 & 2.12 & 0 & 0 & 154 \\
\hline \multicolumn{8}{|l|}{ Habitat trees } \\
\hline \multirow[t]{2}{*}{ Conservationists } & Oak & 49 & 68.8 & 5.66 & 2.6 & 36 & 743 \\
\hline & Hornbeam & 1 & 24.0 & 0.40 & 3.0 & 21 & 24 \\
\hline \multirow[t]{2}{*}{ Foresters } & Oak & 41 & 62.1 & 4.46 & 2.5 & 33 & 386 \\
\hline & Hornbeam & 19 & 25.6 & 0.46 & 1.0 & 11 & 28 \\
\hline
\end{tabular}

Note the 0-values for the mean habitat values of beech, which are a result of the fact that a tree's habitat value is calculated based the occurrence of TreMs, which were absent on these trees

but habitat trees retained by foresters have a lower economic value partly due to foresters including more hornbeams, with low economic and habitat value.

\section{The trade-off between economic and ecological goals}

Regarding trees selected for removal, foresters obtained a significantly higher economic revenue per habitat point as compared to conservationists ( $\mathrm{t}$-test: $\mathrm{p}=0.010$ ). Regarding the habitat tree selection, the opportunity cost of a habitat point was significantly lower for foresters compared to conservationists (t-test: $p=0.030$, Fig. 4), which means that on average conservationists retained a unit habitat value at a higher economic cost.

Figure 5 plots the aggregated habitat and economic values of the sets of habitat trees selected by the different teams (the information underlying this plot can be found in Table 4). It is important to note that only those teams' results (i.e. positions in figure) with exactly 10 habitat trees retained (teams C1, C4, C5, F1, F2 and F3) can be fully compared to the circular line of diamond shaped points, which depicts an approximation of the boundary of the set of all possible combinations of 10 trees. ${ }^{1}$ This approximation is sufficient to show that most of the teams have actually selected a combination of trees that is positioned towards the lower right area of the entire set of possible combinations. Solutions lying in that direction combine a low economic with a high ecological aggregated value, which means that they reconcile the trade-off between habitat retention and forgone timber value better. Apart from some exceptions (such as teams C2 and F6), the

\footnotetext{
1 This approximation is necessary as the aggregated values for all possible combinations is too large to be fully computed. At the bottom and in the lower right quadrant of the plot, the values of combinations of such 10 trees are shown that exhibit an economic value lying within the range from the 7 th percentile on downwards and habitat points lying within the range from the 93th percentile on upwards. A corresponding approximation has been applied also for the other regions of the plot.
} 
Fig. 4 Opportunity cost of one habitat point of the retained habitat trees for foresters and conservationists

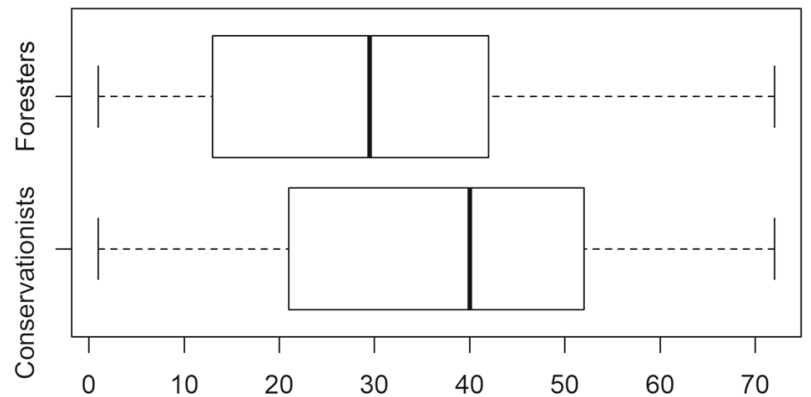

Opportunity cost of a habitat point (Euro)

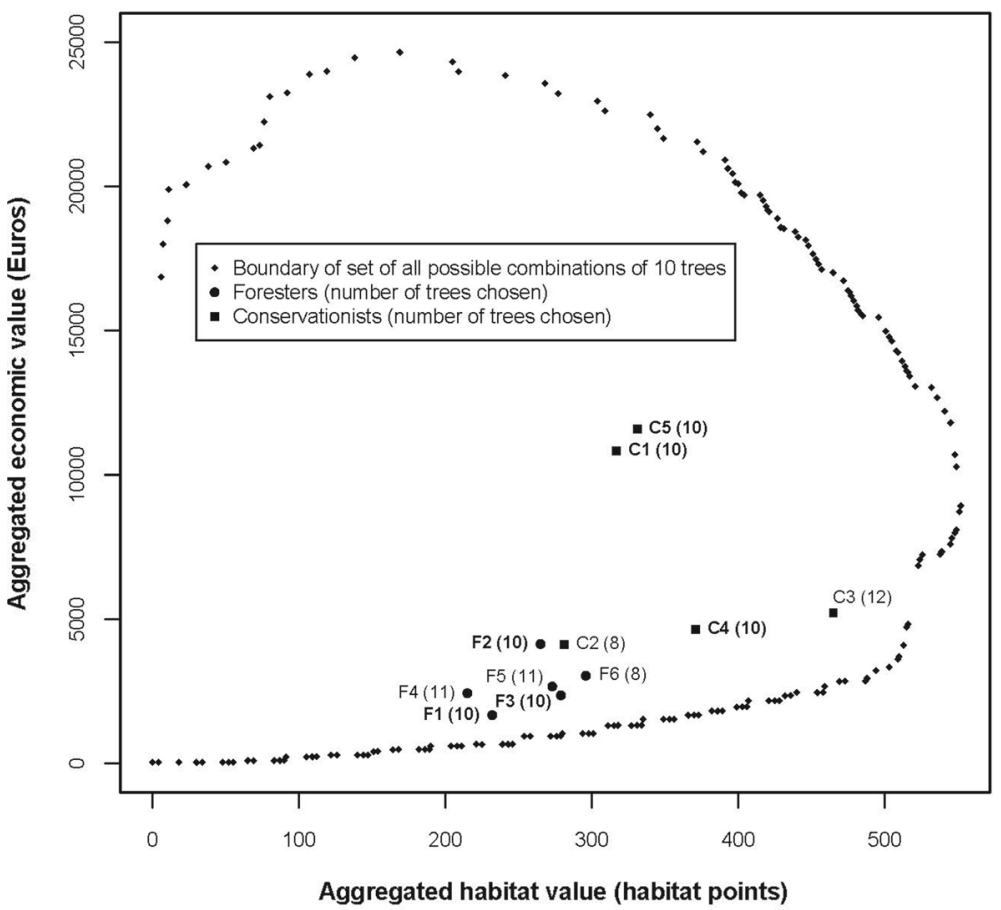

Fig. 5 Aggregated habitat and economic values resulting from the selection of habitat trees by teams of foresters (F1-F6) and conservationists (C1-C5). The diamond shaped points depict an approximation of the boundary of the vast set of aggregated economic and ecological value combinations of all possible selections of 10 trees in the marteloscope. Note that only teams with an equal number of trees should be compared directly and only those with exactly 10 chosen trees (bold label) should be compared to the boundary points in this graph

results achieved by foresters and conservationists are rather distinct. The foresters are located towards the lower-left part of the plot. That is, they have retained less habitat value at lower opportunity costs during the exercise. The conservationists are located more towards the upper-right angle of the plot. That is, they have retained a higher number of habitat points at the cost of waiving a larger amount of potential income. 


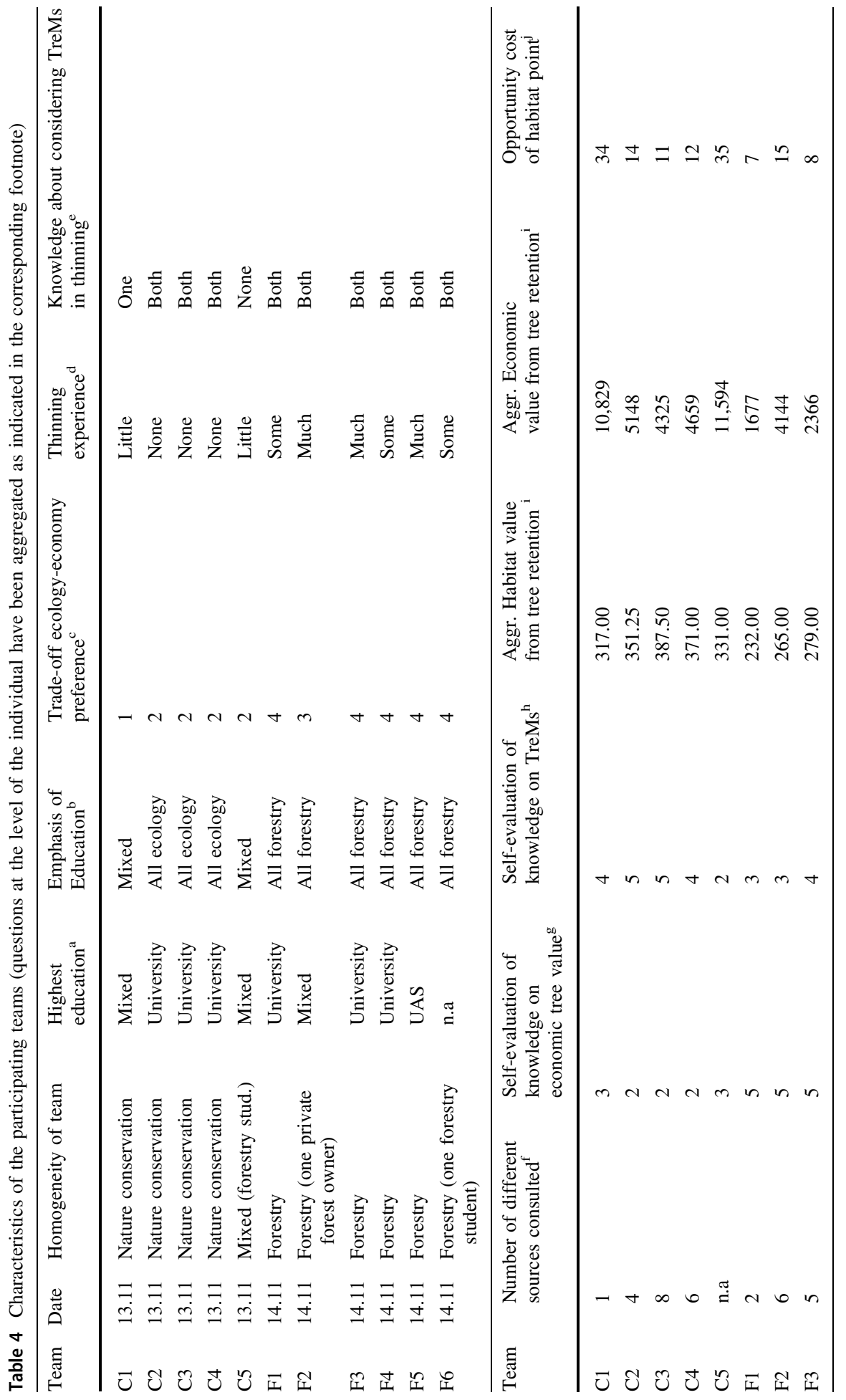




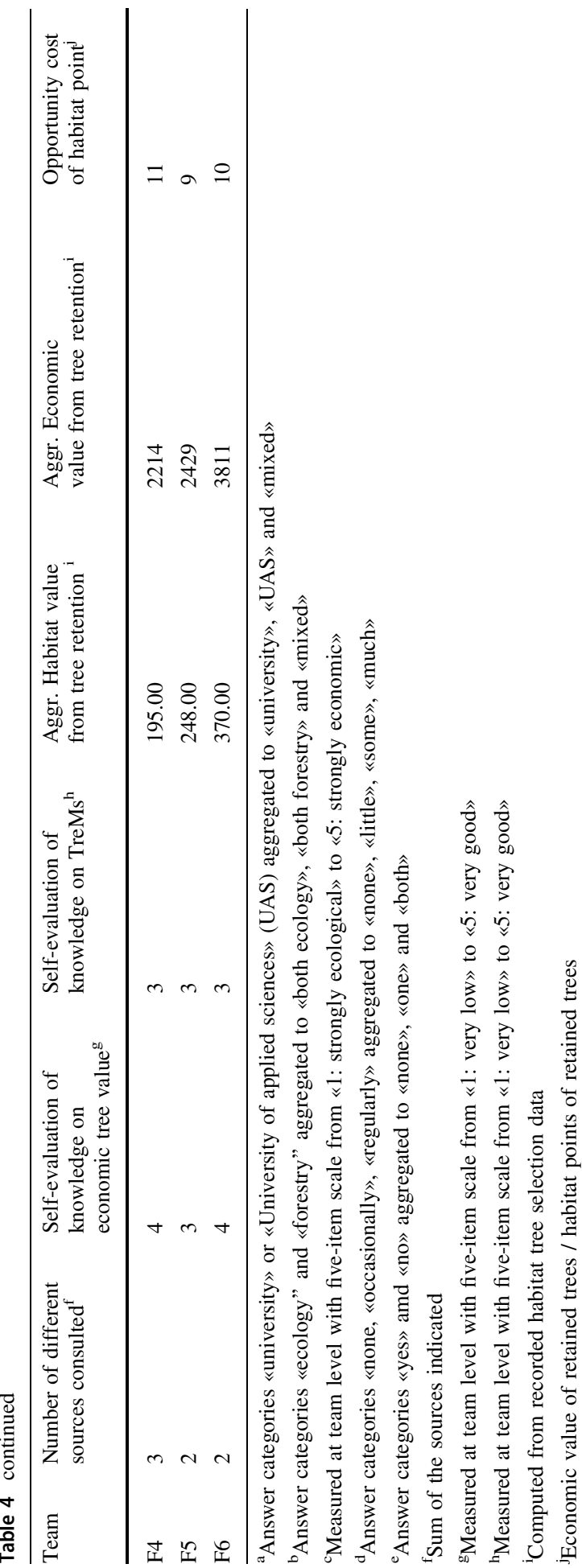




\section{Results from qualitative data analysis-tree selection strategies}

The group discussions following the marteloscope exercises provide deeper insights into the reasons for the observed tree selection. In this section, we present these insights seeking to answer the questions which criteria and strategies the participants apply in tree selection, and how they deal with the trade-off between timber production and forest biodiversity. Insofar these aspects were also covered by the standardized questionnaire participants responded to (see method section), this information is added to the text.

\section{Criteria applied in tree selection}

While monetary criteria were important for all participants when selecting trees to be thinned, their relevance for habitat tree selection varied widely. The group of conservationists barely addressed the economic costs of retaining a habitat tree in the concluding group discussion. In contrast, opportunity cost was mentioned repeatedly as a relevant criterion for foresters' habitat tree selection. They argued that structures apparently diminishing timber value were considered a key criterion for retaining a tree. This difference is reflected in a quote by a nature conservationist: "Usually I do not care much if a tree is [economically] valuable [...] Yet, the comparison is interesting, in order to see in which conflict foresters are when trying to earn money with the forest". Data from the questionnaires confirm these findings, showing that foresters put more emphasis on the economic than on the ecological dimension in dealing with the ecology-economy trade-off (Table 4) and that conservationists considered the economic values much less during habitat tree selection (Table 7 in appendix). In line with this, argumentation based on structural criteria (namely DBH and tree vitality) was used very differently by the participants. Foresters referred to large DBHs as a reason to harvest trees in order to avoid the risk of diminishing timber value through wood defects in the future, thus emphasising economic considerations. In contrast, conservationists argued that larger DBHs increase the probability of a tree to develop microhabitat structures-especially those that take long time to develop - thus arguing for the retention of these trees. Similarly, the criteria vitality and stability were used for contrasting argumentations. Foresters argued to harvest trees as long as they are healthy, which means that "trees are actually still young when we cut them". Economically speaking, a tree's vitality is important to guarantee both its timber quality and the stability of the stand. However, a tree's vitality also increases the chances that TreMs will be provided for a very long time. Interestingly, both groups were referring to vitality also when justifying the retention of what they called "future habitat trees".

As far as ecological criteria are concerned, conservationists stated that they focus primarily on ecologically valuable structures when selecting habitat trees. In contrast, several foresters emphasized that they did not search for individual structures, but rather focused on the whole stand, claiming to take a more holistic view. The descriptions of the foresters' selection criteria remained rather vague, though: their choice of habitat trees seems to result from a mixture of experiential knowledge and related intuition not made explicit. Criteria related to everyday working experience such as traffic and working security are assumed to be part of the consideration process. This is also reflected in the survey data as this aspect was given much more weight by the foresters (Table 7).

As described in the previous section, conservationists almost exclusively selected oaks as habitat trees, while foresters often included hornbeams, whose average economic value 
was 13 times lower compared with oak. One forester argued, for example, that "hornbeams, which are only considered as a decorative accessory from a forestry point of view, [...] can have an incredibly high ecological value here." This perspective was not confirmed by the quantitative data at least as far as the current ecological value is concerned: on average the amount of TreMs, and habitat value of the selected hornbeams was three times lower compared to the oaks (see Sect. Designation of habitat trees and Table 3).

Summing up, foresters tend to evaluate TreMs somewhat differently than the conservationists. Although conservationists considered themselves somewhat more competent concerning TreMs and tend to inform themselves from more sources, the foresters still consider their own knowledge to be medium to high and they also indicated to consult at least two and even more sources on that topic (Table 4).

\section{Strategies and approaches in tree selection}

One obvious strategy applied was prioritization. In the group discussions, some participants reported to search first and foremost for specific criteria, such as economically valuable trees, wood defects or microhabitat structures, while subordinating other criteria. Interestingly, these participants still underlined the chances of integrating various goals within their approach, without perceiving this as contradictory to their rather clear prioritization.

Other participants (of both groups) placed a strong emphasis on balancing goals. Since economic and ecological objectives cannot be reconciled on one and the same tree, their strategy focused on achieving a balance at stand level. One conservationist described a continuous weighing process that often sounded like bartering: "Considering what other high-quality structures can be found in the stand, we can sacrifice this tree [...] and have thereby already achieved a relatively high economic added value allowing us to retain more other trees in the stand, which are ecologically more valuable."

Finally, the observed strategies differ according to their temporal perspective. Assuming that "each tree will develop habitat structures if you leave it long enough", conservationists argued to retain trees whose ecological value is not high yet, but will be in the future when microhabitat structures develop. In contrast, the foresters argued to harvest trees before the appearance of those structures, which they perceive as wood defects. They themselves mentioned the argument to give emphasis to the development of future microhabitat structures on those trees whose economic value was already considered low now and in the future. Correspondingly, the foresters had indicated in the questionnaire that they put much more weight on the future economic value of a tree during habitat tree selection (Table 7). This became obvious, for instance, when participants discussed about a big, spirally grown oak. One of the foresters described his assessment of the tree as follows: "This [oak] has a real strong spiral grain. That means the [economic] value is very limited [...] this strong, steep branch might break off sometime, thinking a bit into the future. This would be such a tree that may become a methuselah tree."

\section{Factors influencing strategies and approaches in tree selection}

Both groups discussed the importance of being familiar with the stand characteristics as an important factor influencing tree retention and harvesting strategies. One forester emphasized that local experience is crucial to assess the interrelation between oak DBHs and the risk of decreasing vitality, which, from an economic perspective, is essential for 
deciding about the time of harvesting. One of the conservationists recognized that the DBH of the trees he had selected for harvesting were too small, which he attributed to his lack of knowledge about size class distribution within the stand.

Although both groups underlined the importance of visual aspects in tree selection, foresters were hardly equipped with binoculars, while conservationists made intensive use of them. When asked about this different approach, the foresters made clear that time restrictions in their real work life make it impossible to look at all structures in detail, so that some are inevitably overlooked. Yet, they assumed that their holistic view and experience will compensate for this.

In addition to these rather individual factors, the stand context in general has a strong influence on the tree selection strategy. Trade-offs especially occur if a stand's TreMs are concentrated on only a few trees with high economic value. Obviously, in such a situation a decision can be facilitated by adapting the definition of a habitat tree in a way that allows designating trees with lower habitat or higher economic value. In that respect the following quote of a forester is telling: "You have no problem to find a sufficient number of habitat trees here in this stand. This is a luxury problem".

\section{Discussion}

The most striking result of the conducted exercise was the remarkably different selection strategies concerning habitat trees; hence we focus on this aspect in the discussion.

\section{What qualifies a tree as a habitat tree?}

Although there have been attempts to define a habitat tree (Bütler et al. 2013), to a certain extent the existing definitions allow for personal interpretation, especially when it comes to practical implementation.

In the group discussion, the conservationists argued that the oak trees, with a large $\mathrm{DBH}$, already exhibit valuable TreMs and that they have the highest potential to develop even more valuable microhabitats in the future. This in line with scientific research showing an increase in the occurrence and abundance of TreMs with the increasing tree diameter (Asbeck et al. 2019; Santopuoli et al. 2019). Internal guidelines of biodiversity conservation organizations in the region recommend a minimum diameter of $70 \mathrm{~cm}$ for a habitat tree and its definition also encompasses standing deadwood (BSBRE 2014). The regional foresters' organization, in contrast, recommends $40 \mathrm{~cm}$ as such a minimal diameter (Herzig 2014). Still, many of the designated hornbeams, identified as habitat trees by the foresters, were below that threshold. Given the much lower economic value of the hornbeams, the selection strategy of the foresters was obviously also targeting at minimizing opportunity costs for habitat trees. In the group discussion, the foresters confirmed that they often rely on the opportunity cost of a habitat point to reconcile the trade-off situation at hand. The conservationists, however, barely addressed this topic.

These findings suggest that clearer definitions and categorizations of habitat trees and TreMs (Larrieu et al. 2018) as key characteristics of these trees would certainly be beneficial to increase agreement between foresters and conservationists on this issue. Yet, at the same time, the concept and selection of habitat trees has to remain adaptive. For instance, a small cavity tree could be considered a valuable habitat tree in a stand with very few TreMs, but the same tree will receive less attention in an old growth stand with many large trees bearing multiple TreMs. 


\section{Projection of TreMs development into the future}

In contrast to opportunity costs, the issue of future development of the forest was equally addressed by all participants. Over time, there is an increase in the chances of habitat structures to evolve. Long-term development was therefore perceived as a valid argument to retain trees with currently rather few habitat structures. Again, however, the two groups applied this strategy in different ways, consistent with their respective convictions. The conservationists argued that selecting large trees will support the future development of TreMs, as large trees are more likely to develop and maintain a wide variety of such structures. In contrast, the foresters used the projection of future habitat value for justifying the selection of smaller and currently ecologically less valuable hornbeams as habitat trees.

These justifications stand in contrast to social science research findings indicating that forest managers often consider a relatively limited future time-frame (10-20 years) in their forest planning (Hoogstra and Schanz 2009), and to the observed lack of scientific knowledge regarding habitat values and how TreMs develop over time (Courbaud et al. 2017; Larrieu et al. 2017, 2018). This possibly indicates that both conservationists and foresters were drawing on a far-away future in a manner that made current decisions consistent with their professional beliefs. More scientific information about how habitats develop over time would thus greatly benefit decision-making.

\section{Limitations of the study and suggestions for further research}

Considering the case-study character and the small sample size of our study, any generalizing statements seem premature. However, the main finding of our exercise is obvious: although they received the same assignment, conservationists and foresters took strikingly different decisions in balancing habitat retention and wood production. We thus expect this pattern to play an important role also beyond the specific case. The stand used for the exercise is typical for economically managed oak stands in a similar development phase. It would be interesting, though, to replicate the exercises also in other forest types, to get a broader and more nuanced understanding of how the differences between foresters and conservationists play at a larger scale.

Finally, we cannot tell if and how decision-making would change in comparison to our recorded data under real-life conditions (Mukherjee et al. 2018), where, for instance, time constraints play a bigger role, and firm habituated routines might replace careful, reflexive tree selection. Comparing our findings with tracing real-life tree selection decisions could help to correlate our artificial decision-making situation to management reality.

Our research contributes to social science research about how forest managers cope with the time frame and the underlying uncertainties for rationalizing their decisions (Wagner et al. 2014), and our results indicate that mixed methods research using marteloscope sites can advance our respective understanding. In such a setting, more explicit experimental research designs could vary stand and tree characteristics and instructions in a way that allows to draw firmer conclusions about the relative impact of professional expertise and individual preferences. Deepening the qualitative data gathering, for example by interviewing single participants or teams during tree selection, would allow to better link observed tree-selecting behaviour and underlying justifications. 


\section{Conclusions: resolving the production-conservation trade-off}

While habitat tree selection in continuous cover forestry is mainly done by forest managers in Europe, conservationists are more and more involved in this task. Our study provides a first insight into the possible outcomes of tree selection processes by either foresters or conservationists. Conservationists tended to focus on the ecological value, thus retaining habitat trees with larger diameter and higher habitat scores as compared to the foresters. These trees might be a preferred object for biodiversity conservation (Grossmann et al. 2018), but they also constitute a higher renouncement in economic terms.

Our analysis shows that neglecting economic perspectives in tree selection can have considerable economic consequences. We have indications that this difference is not simply a consequence of being ignorant about habitat or economic values, but also a consequence of fundamentally differing preferences, as well as assumptions about the future habitat value of certain trees and tree species.

Economic objectives have dominated the history of professional forest management in Europe, resulting in the formation of professional biases and habituated routines to maximize long-term economic revenues, and the use of quantifiable indicators for its assessment. Figures on wood volume and increment are collected on a regular basis and are used to evaluate both the enterprise and the individual foresters' performance. In contrast, forest managers' performance related to biodiversity conservation is hardly ever evaluated in comparably quantified terms. Hence, whereas foresters have found to be able to estimate trees' economic value, assessing the ecological value remains often more difficult (2010). Developing more specific benchmarks to measure and evaluate ecological goals, possibly involving quantification, could be helpful and rewarding for the foresters. This is as they might provide a counterweight to often dominant financial and timber oriented targets and expectations (cf. Maier and Winkel 2017). This is reflected in the suggestion of a forester participating in the training exercise: "[We have to] give the ecological part a value, in some comparable form" and "We must have some benchmark, since, we as economists are assessed by our economic performance". The habitat value calculation used in this study could provide the basis for such ecological benchmarks.

While the exercises unveiled undeniable differences in habitat tree selection between foresters and conservationists, the participants were certainly willing to learn, as the following quote of a nature conservationist illustrates: "I find it relieving [...] to remember the exercise and reflect on what it economically means [to retain a habitat tree], then this may eventually help to decide, if a tree is [to be retained as] a habitat tree or not". We thus are confident that effective integration of biodiversity conservation in forests can be fostered by improved education for foresters and conservationists about the motivations and restrictions of the respective counterpart.

Against this background, tools such as marteloscopes have great potential to make the trade-off (and synergies) between conservation and forest (biomass) production visible in a concrete forest stand. They provide the opportunity to make actors aware of their professional routines and related biases of both sides, and offer them a more differentiated perception of the trade-off at hand which facilitates finding compromises. Most probably, this could be even more the case if tree selection exercises would be conducted in 
interdisciplinary teams. This would allow for mutual learning and thus foster a deeper cooperation between different professional groups.

Acknowledgements We warmly thank all participants and organizers of the marteloscope exercise. Thanks to Liska Beulshausen for transcriptions and Anne Paulus for supporting qualitative data analysis. We also gratefully acknowledge the financial support for this research provided by the Swiss Federal Research Institute for Forest Snow and Landscape WSL [Project ID 1244], the German Research Foundation (DFG) through the Research Training Group ConFoBi (Conservation of Forest Biodiversity in Multiple-Use Use Landscapes of Central Europe) [Grant number GRK 2123/1 TPX], and the German Federal Ministry for Food and Agriculture (BMEL) under the Integrated Forest Management Learning Architecture (INFORMAR) project (contract number Forst-2017-1). Last but not least, we warmly thank the anonymous reviewers for their valuable and constructive comments.

Author contributions $\mathrm{CH}, \mathrm{ST}, \mathrm{KF}, \mathrm{SA}, \mathrm{JB}$ and MR conceived and designed the marteloscope exercise. $\mathrm{CH}$, $\mathrm{KF}, \mathrm{SA}, \mathrm{JB}$ and MR were present during the exercise. Data analysis was performed by $\mathrm{CH}$ and ST (quantitative data) and JB and MR (qualitative data). C., ST and JB wrote the paper draft and led the writing, while KF, SA, MR and WG contributed to the writing with revisions.

Funding Open Access funding provided by Lib4RI - Library for the Research Institutes within the ETH Domain.

Open Access This article is licensed under a Creative Commons Attribution 4.0 International License, which permits use, sharing, adaptation, distribution and reproduction in any medium or format, as long as you give appropriate credit to the original author(s) and the source, provide a link to the Creative Commons licence, and indicate if changes were made. The images or other third party material in this article are included in the article's Creative Commons licence, unless indicated otherwise in a credit line to the material. If material is not included in the article's Creative Commons licence and your intended use is not permitted by statutory regulation or exceeds the permitted use, you will need to obtain permission directly from the copyright holder. To view a copy of this licence, visit http:// creativecommons.org/licenses/by/4.0/.

\section{Appendix}

See Tables 5, 6 and 7.

Table 5 Contingency table: tree species x Participant group for removed trees (absolute and contingent frequencies)

\begin{tabular}{lll}
\hline & Group & \\
\cline { 2 - 3 } & Conservationists & Foresters \\
\hline Tree species & & \\
Hornbeam & $30(32 \%)$ & $13(16 \%)$ \\
Beech & $7(7 \%)$ & $6(8 \%)$ \\
Oak & $58(61 \%)$ & $61(76 \%)$ \\
Total & 95 & 80 \\
\hline
\end{tabular}


Table 6 Contingency table: Tree species $\times$ Participant group for habitat tree selection (absolute and contingent frequencies)

\begin{tabular}{lll}
\hline & Group & \\
\cline { 2 - 3 } & Conservationists & Foresters \\
\hline Tree species & & \\
Hornbeam & $1(2 \%)$ & $19(32 \%)$ \\
Oak & $49(98 \%)$ & $41(68 \%)$ \\
Total & 50 & 60 \\
\hline
\end{tabular}

Chi-square $\mathrm{p}<0.001$

Table 7 Importance of tree selection criteria as retrospectively indicated by participating teams (mean values) in the questionnaire. $1=$ not important; 2 = less important; 3 = very important

\begin{tabular}{|c|c|c|c|c|}
\hline \multirow[t]{2}{*}{ Selection criteria } & \multicolumn{2}{|c|}{ Habitat tree retention } & \multicolumn{2}{|l|}{ Tree removal } \\
\hline & Conservationists & Foresters & Conservationists & Foresters \\
\hline Ecological value & 3.0 & 3.0 & 2.8 & 2.2 \\
\hline Economic value & 1.4 & 2.83 & 2.6 & 3.0 \\
\hline Future ecological value & 3.0 & 2.8 & 2.2 & 2.0 \\
\hline Future economic value & 2.0 & 2.6 & 2.8 & 2.66 \\
\hline Spatial distribution of habitat trees & 2.4 & 2.33 & 2.0 & 1.83 \\
\hline Working security & 2.0 & 2.0 & 1.8 & 2.0 \\
\hline Traffic security & 1.6 & 2.0 & 1.6 & 2.0 \\
\hline Stability of the stand & 2.0 & 2.0 & 2.8 & 2.5 \\
\hline Promotion of diversity of structure & 2.8 & 2.5 & 2.2 & 2.5 \\
\hline Control of composition of tree species & 2.0 & 1.83 & 2.2 & 2.0 \\
\hline
\end{tabular}

\section{References}

Asbeck T, Pyttel P, Frey J, Bauhus J (2019) Predicting abundance and diversity of tree-related microhabitats in Central European montane forests from common forest attributes. Forest Ecol Manag 432:400-408. https://doi.org/10.1016/j.foreco.2018.09.043

Bauhus J, Puettmann K, Messier C (2009) Silviculture for old-growth attributes. Forest Ecol Manag 258:525-537. https://doi.org/10.1016/j.foreco.2009.01.053

Bennett NJ et al (2017) Conservation social science: understanding and integrating human dimensions to improve conservation. Biol Conserv 205:93-108. https://doi.org/10.1016/j.biocon.2016.10.006

Bohnsack R, Pfaff N, Weller W (2010) Qualitative analysis and documentary method in international educational research. Barbara Budrich Publishers, Opladen and Farmington Hills, MI

Brewer EW, Kuhn J (2010) Causal-comparative design. In: Salkind NJ (ed) Encyclopedia of researchdesign. SAGE, Thousand Oaks, pp 124-131

BSBRE (2014) Jahresbericht. Biologische Station Bonn/Rhein-Erft e.V, Bonn

Bütler R, Lachat T, Larrieu L, Paillet Y (2013) Habitat trees: key elements for forest biodiversity. In: Kraus D, Krumm F (eds) Integrative approaches as an opportunity for the conservation of forest biodiversity. Joensuu, European Forest Institute, pp 84-91

Charnley S et al (2017) Evaluating the best available social science for natural resource management decision-making. Environ Sci Policy 73:80-88 
Cosyns H, Kraus D, Krumm F, Schulz T, Pyttel P (2018) Reconciling the tradeoff between economic and ecological objectives in habitat-tree selection: a comparison between students. For For Train For Sci 65:223-234. https://doi.org/10.1093/forsci/fxy042

Courbaud B, Pupin C, Letort A, Cabanettes A, Larrieu L (2017) Modelling the probability of microhabitat formation on trees using cross-sectional data. Methods Ecol Evol 8:1347-1359. https://doi.org/10. 1111/2041-210x.12773

Creswell JW, Clark VLP (2017) Designing and conducting mixed methods research. Sage, London

Grossmann J, Schultze J, Bauhus J, Pyttel P (2018) Predictors of microhabitat frequency and diversity in mixed mountain forests in South-Western Germany. Forests. https://doi.org/10.3390/f9030104

Gustafsson L et al (2012) Retention forestry to maintain multifunctional forests: a world perspective. Bioscience 62:633-645. https://doi.org/10.1525/bio.2012.62.7.6

Gustafsson L et al (2020) Retention as an integrated biodiversity conservation approach for continuouscover forestry in Europe. Ambio 49:85-97. https://doi.org/10.1007/s13280-019-01190-1

Herzig B (2014) Biotopholzstrategie Xylobius Nordrhein-Westfalen Alt- und Totholz für den Landeswald. Wald und Holz NRW, Münster

Hoogstra MA, Schanz H (2009) Future orientation and planning in forestry: a comparison of forest managers' planning horizons in Germany and the Netherlands. Eur J Forest Res 128:1-11

InForMAr (2018) Marteloscopes Sites. European Forest Institute. https://informar.eu/marteloscope-sites map. Accessed Nov 152018

Ivanoff SD, Hultberg J (2006) Understanding the multiple realities of everyday life: Basic assumptions in focus-group methodology. Scand J Occup Ther 13:125-132

Kraus D et al (2016a) Catalogue of tree microhabitats-reference field list. Euro For Inst. https://doi.org/10. 13140/RG.2.1.1500.6483

Kraus D, Mergner U, Schuck A, Krumm F, Haussmann T (2016) Integrate+: Wieviel Naturschutz kann der bewirtschaftete Wald leisten? Der Dauerwald - Zeitschrift für naturgemäße. Waldwirtschaft 54:33-38

Kraus D et al (2018) Seeing is building better understanding-the Integrate+ Marteloscopes. European Forest Institute, Joensuu

Kruse J (2015) Qualitative interviewforschung. Ein integrativer Ansatz. Beltz Juventa, Weinheim and Basel

Lamnek S (2005) Gruppendiskussion: Theorie und Praxis (2., überarb. und erw. Aufl.). UTB Psychologie, Pädagogik, Soziologie: Vol. 8303. Beltz

Larrieu L, Cabanettes A, Gouix N, Burnel L, Bouget C, Deconchat M (2017) Development over time of the tree-related microhabitat profile: the case of lowland beech-oak coppice-with-standards set-aside stands in France. Eur J Forest Res 136:37-49. https://doi.org/10.1007/s10342-016-1006-3

Larrieu L et al (2018) Tree related microhabitats in temperate and Mediterranean European forests: a hierarchical typology for inventory standardization. Ecol Indic 84:194-207. https://doi.org/10.1016/j. ecolind.2017.08.051

Lassauce A, Lieutier F, Bouget C (2012) Woodfuel harvesting and biodiversity conservation in temperate forests: effects of logging residue characteristics on saproxylic beetle assemblages. Biol Conserv 147:204-212. https://doi.org/10.1016/j.biocon.2012.01.001

Maier C, Winkel G (2017) Implementing nature conservation through integrated forest management: a street-level bureaucracy perspective on the German public forest sector. For Pol Econ 82:14-29

Mascia MB, Brosius JP, Dobson AT, Forbes BC, Horowitz L, McKean MA, Turner NJ (2003) Conservation and the social sciences. Conserv Biol 17:649-650

Mayring P (2014) Qualitative content analysis: theoretical foundation, basic procedures and software solution. Belz, Klagenfurt

Merriam SB (2009) Qualitative research: a guide to design and interpretation. Jossey-Bass, San Francisco

Mukherjee N, Zabala A, Huge J, Nyumba TO, Esmail BA, Sutherland WJ (2018) Comparison of techniques for eliciting views and judgements in decision-making. Methods Ecol Evol 9:54-63. https://doi.org/10. 1111/2041-210x.12940

Niedermann-Meier S, Mordini M, Bütler R, Rotach P (2010) Habitatbäume im Wirtschaftswald: ökologisches Potenzial und finanzielle Folgen für den Betrieb. Schweizerische Zeitschrift fur Forstwesen 161:391-400. https://doi.org/10.3188/szf.2010.0391

Nyumba TO, Wilson K, Derrick CJ, Mukherjee N (2018) The use of focus group discussion methodology: insights from two decades of application in conservation. Methods Ecol Evol 9:20-32. https://doi.org/ 10.1111/2041-210x.12860

Pommerening A, Pallares Ramos C, Kedziora W, Haufe J, Stoyan D (2018) Rating experiments in forestry: how much agreement is there in tree marking? PLoS One 13:e0194747. https://doi.org/10.1371/ journal.pone.0194747

Puettmann KJ et al (2015) Silvicultural alternatives to conventional even-aged forest management-what limits global adoption? For Ecosyst. https://doi.org/10.1186/s40663-015-0031-X 
Santopuoli G, di Cristofaro M, Kraus D, Schuck A, Lasserre B, Marchetti M (2019) Biodiversity conservation and wood production in a Natura 2000 Mediterranean forest. A trade-off evaluation focused on the occurrence of microhabitats. Iforest 12:76-84. https://doi.org/10.3832/ifor2617-011

Schaber-Schoor G (2010) Fachliche Anforderungen Ziele und Handlungsansätze verschiedener Alt- und Totholzkonzepte. AFZ-DerWald 65:8-9

Schuck A, Krumm F, Kraus D (2015) Integrate+ Marteloscopes: description of parameters and assessment procedures. European Forest Institute, Joensuu

Spinelli R, Magagnotti N, Pari L, Soucy M (2016) Comparing tree selection as performed by different professional figures. Forest Sci 62:213-219. https://doi.org/10.5849/forsci.15-062

Tashakkori A, Teddlie C (2010) Sage handbook of mixed methods in social \& behavioral research. Sage, London

Vitkova L, Dhubhain AN, Pommerening A (2016) Agreement in tree marking: what is the uncertainty of human tree selection in selective forest management? Forest Sci 62:288-296. https://doi.org/10.5849/ forsci.15-133

Wagner S, Nocentini S, Huth F, Hoogstra-Klein M (2014) Forest management approaches for coping with the uncertainty of climate change: trade-offs in service provisioning and adaptability. Ecol Soc. https:// doi.org/10.5751/Es-06213-190132

Winter S, Borrass L, Geitzenauer M, Blondet M, Breibeck R, Weiss G, Winkel G (2014) The impact of Natura 2000 on forest management: a socio-ecological analysis in the continental region of the European Union. Biodiv Conserv 23:3451-3482. https://doi.org/10.1007/s10531-014-0822-3

Publisher's Note Springer Nature remains neutral with regard to jurisdictional claims in published maps and institutional affiliations.

\section{Affiliations}

\section{Hannes Cosyns ${ }^{1}$ (D) Bettina Joa ${ }^{2} \cdot$ Ronja Mikoleit $^{3} \cdot$ Frank Krumm $^{1} \cdot$ Andreas Schuck ${ }^{2} \cdot$ Georg Winkel ${ }^{2} \cdot$ Tobias Schulz $^{1}$}

\section{Hannes Cosyns}

hannes.cosyns@wsl.ch

1 Swiss Federal Research Institute for Forest, Snow and Landscape Research (WSL), Research Unit Economics and Social Sciences, Zürcherstrasse 111, 8903 Birmensdorf, Switzerland

2 European Forest Institute (EFI), Platz der Vereinten Nationen 7, 53113 Bonn, Germany

3 Faculty of Environment and Natural Resources, University of Freiburg, Albert-Ludwigs-University Freiburg, Tennenbacher Straße 4, 79106 Freiburg, Germany 